\title{
Erratum to: Teachers' assessments of children aged eight predict life satisfaction in adolescence
}

\author{
Meri Honkanen - Tuula Hurtig • Anja Taanila • Irma Moilanen • \\ Hannu Koponen · Pirjo Mäki · Juha Veijola • Anita Puustjärvi • \\ Hanna Ebeling $\cdot$ Heli Koivumaa-Honkanen
}

Published online: 26 March 2013

(c) Springer-Verlag Berlin Heidelberg 2013

\section{Erratum to: Eur Child Adolesc Psychiatry (2011) 20:469-479 \\ DOI 10.1007/s00787-011-0200-6}

Unfortunately, the given and family names of the authors have been inadvertently interchanged in the original version. The correct names in the author group should read as given below:

Meri Honkanen · Tuula Hurtig · Anja Taanila · Irma Moilanen · Hannu Koponen · Pirjo Mäki · Juha Veijola . Anita Puustjärvi · Hanna Ebeling · Heli KoivumaaHonkanen
The online version of the original article can be found under doi:10.1007/s00787-011-0200-6.

\section{Honkanen $(\square)$}

School of Applied Science and Teacher Education,

University of Eastern Finland, Hautalahdenkatu 10 B,

70820 Kuopio, Savonlinna, Finland

e-mail: meri.honkanen@pieksamaki.fi

T. Hurtig $\cdot$ A. Taanila

Institute of Health Sciences,

University of Oulu, Oulu, Finland

T. Hurtig · I. Moilanen · H. Ebeling

Department of Child Psychiatry,

Institute of Clinical Medicine,

University of Oulu, Oulu, Finland

A. Taanila

Unit of General Practice,

Oulu University Hospital, Oulu, Finland

H. Koponen

Department of Psychiatry,

Institute of Clinical Medicine,

University of Eastern Finland, Kuopio, Finland

\section{P. Mäki · J. Veijola · H. Koivumaa-Honkanen}

Department of Psychiatry, Institute of Clinical Medicine,

University of Oulu, Oulu, Finland

P. Mäki

Department of Psychiatry,

Oulu University Hospital, Oulu, Finland
A. Puustjärvi
Department of Child Psychiatry,
Southern Savo Hospital District, Mikkeli, Finland
H. Ebeling
Department of Child Psychiatry,
Oulu University Hospital, Oulu, Finland
H. Koivumaa-Honkanen
Department of Psychiatry,
Lapland Hospital District, Muurola, Finland
H. Koivumaa-Honkanen
Department of Psychiatry,
University Hospital of Kuopio, Kuopio, Finland 